\title{
Multifunctional Power Plant
}

\author{
Tryambak De \\ (Science Department Class XII, Delhi Public School Ruby Park, Kolkata, India)
}

\begin{abstract}
This Multifunctional Power Plant will have unique features. Sea water which is available in abundance in nature is used as a source of energy by utilising solar radiation through the method of photolysis of water. in this multifunctional plant all types of Bio-Waste e.g. agricultural, forest, domestic etc. are also used for production of fertiliser \& biofuel Thus we are able to manage our Bio Wastes. As a byproducts pure water \& salt are also generated which can be used in our society. In the process of power generation there is no emission of Green House Gasses and hence no Green House Effect.
\end{abstract}

\section{Introduction}

This Multifunctional Power Plant will have unique features. Sea water which is available in abundance in nature is used as a source of energy byutilising solar radiation through the method of photolysis of water. in this multifunctional plant all types of Bio-Waste e.g. agricultural , forest, domestic etc. are also used for production of fertiliser\& biofuel Thus we are able to manage our Bio Wastes. As a byproducts pure water \& salt are also generated which can be used in our society. In the process of power generation there is no emission of Green House Gasses and hence no Green House Effect.

\section{Description of the mechanism of the Plant}

1. Sea water is taken through inlets to the water photolysis unit .Here the water is decomposed using Silicon wafers and any other such photo catalysts into Hydrogen and Oxygen .The concentrated salt water is then taken to salt production unit where salt is produced by allowing salt to crystalyse .This Hydrogen gas is then transported by pipes to the Hydrogen storage unit .This Hydrogen is then carried from the storage to the combustion turbine unit where it is burnt to produce steam and turn the turbine and generate electricity. The steam produced is used to heat up the organic dehydrator unit where organic wastes (From Agriculture, Forest and Domestic Waste) are dehydrated. In this process the steam gets condensed and this is then carried to the distilled water storage unit from where it is supplied to the water supply system of the society after addition of essential minerals to it. The dry organic wastes are then heated anaerobically by burning some of the Hydrogen from the storage. As a result the organic wastes get converted to charcoal. During this process the fumes produced contain Nitrogen and Sulphur containing volatile organic compounds which can be used to synthesisfertilisers. The Carbon produced is made to combine with Hydrogen in the presence of suitable catalysts thereby producing Biofuel (Biopetrol\& Biodiesel). 
2. Process flow diagram:

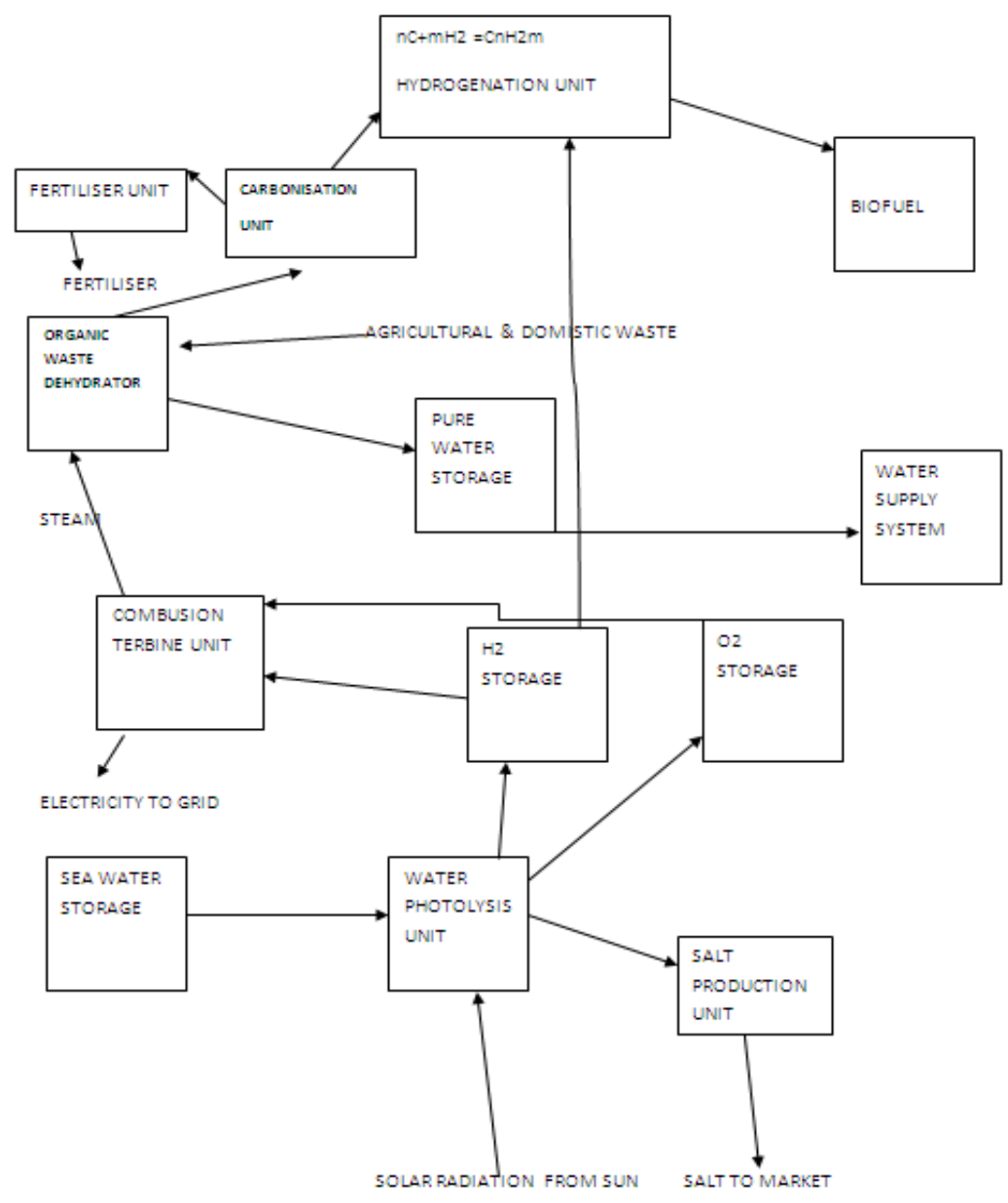

III. Advantages of this plant

- Zero emission of Green House Gases as it is based upon Solar Energy thereby leading to reduced Green House Effect and moreover it conserves non-renewable resources like Coal ,Petroleum and Natural Gas, prevents acid rain as it does not produce $\mathrm{So}_{2}, \mathrm{No}_{2}$, etc and helps to combat Global Warming and save our Mother Earth.

- Produces desalinated water which can be used for domestic purposes. This is particularly useful in states like Gujarat which is close to the sea and dry state and there is severe water crisis.

- Provides effective means of Waste Management \& its proper utilisation of organic wastes like Farm wastes,Forest Waste And Domestic Waste for the production of Biopetrol and Biodiesel and also fertilisers. Thereby solving the problem of import of Petroleum from other countries which in turn reduces the burden on Indian economy and produces opportunities of development. The fertilisers produced this way reduces the consumption of Natural Gas for this purpose which can be used for various other purposes.

- Salt produced can be sold to the market and can give a boost to various other Chemical Industries thereby generating a lot of revenue.

- Provides employment opportunities to a large number of people through the development of this Self Sustaining Plant as it leads to the development of the manufacturing sector in India .Thereby raising per capita income .

- This Plant effectively solves the problem faced by the Production of Electricity only by Photovoltaic Technology as this Plant Can Generate Electricity both at Night and Day.

- The major advantage over the Photovoltaic Technology is that it produces alternating current which can be transmitted over long distances without much loss in energy. Another advantage over the Solar Thermal Technology is that it does not involve loss of heat energy as Hydrogen and Oxygen gases which can be easily stored and can be used at Night to sustain the Power Production at Night. 
- The Biofuels (Petrol And Diesel) produced by this Plant will help to reduce the burden on the Indian Economy as the need to import Petroleum will be reduced, thereby it would also counter the price hike in India.

\section{Conclusion}

Thus it can be concluded that the development of this Single Plant can solve a large number of problems faced by India at present, though the initial cost of setting this up is high but this Plant generates revenue througha multitude of products which is much greater than the running cost of the Plant. Moreover there is no recurring cost as the Plant uses raw materials like Sea Water, Sunlight and Organic Wastes which are free of cost and are abundantly available. Moreover this will also help in conserving the Non-Renewable Resources like coal, Petroleum and Natural Gas thereby protecting the Environment and provides a base for the development of various other industries based on the products produced by this industry, thus giving a boost to the development of the secondary sector in India. Also it is Self Sustaining Unit and the Revenue Generated by one such Plant will provide the fund for setting up other such plants thereby increasing the income of the Nation. For this Project to come up requires the investment by the Government or Private Companies or as Joint Ventures thereby benefitting both the Government and the Nation as a whole. 